\begin{tabular}{|c|c|c|}
\hline & $\begin{array}{c}\text { International Journal of Current Research in } \\
\text { Biosciences and Plant Biology }\end{array}$ \\
\hline EXCELLENT \\
PUBLISHERS
\end{tabular}

\title{
e-Working Environment: A Present Way of Life
}

\author{
Arvind Bijalwan $^{1}$, Manmohan J. R. Dobriyal ${ }^{2}$ and Pradeep Chaudhry ${ }^{1}$ \\ ${ }^{1}$ Indian Institute of Forest Management, Nehru Nagar, Bhopal-462003, M.P., India, \\ ${ }^{2}$ Department of Silviculture and Agroforestry, College of Forestry (ACHF), Navsari Agricultural University, Navsari-396450, \\ Gujarat, India
}

*Corresponding author.

\begin{abstract}
e-working environment deals with electronic working environment. Today it has become an integral part of our life style and we cannot imagine performing most of the tasks without use of electronic gadgets. On the other hand excess use of electronic gadgets and its relationship between changes in life style is also concern to the human health. In our opinion $e$-working is need of the time but requires equilibrium between working style and human health.
\end{abstract}

\section{Article Info}

Accepted: 20 December 2016

Available Online: 06 January 2017

Keywords

e-domain

Electronic gadgets

e-working environment

Human health

Paperless working

\section{Introduction}

Visualise yourself, how do you feel while reading a news paper with a cup of tea during morning sunlight in your lawn or in an open space? Of course, must enjoy the tea in a natural environment. Now again imagine, if you are reading an electronic (e) news paper with similar situation, how do you feel? The question is about electronic (e) environment and our way of life. The $e$ working has become an integral part of our life style and we imagine completing every task under e-environment only. There are countless instances of $e$-working such as paperless workings are known to everyone add some more. But at the same time the doctors' community is worried about the relationship between changes in life style under $e$-working environment (excess use of electronic gadgets etc) and its impact to human health.
Even the researches in the medical science articulate that if we work for a longer time on mobile and laptop etc, we can also be threatened by many physical disorders. Moreover, researches in medical field found that significant number of males suffering from infertility syndrome for which mobile radiation and e-working environment are the major reasons.

\section{$e$-Working environment}

It is indeed a matter of great concern which needs further discussion and deliberation, whether to completely adopt the $e$-working environment or go away with it (which is almost impractical). Then what to do? Can we imagine today's life without $e$-working environment that too when the space is full of electronic ways engendered by human being in the age of science 
and technology. The impact is more severe to the scientific community and academicians, who are habitual of electronic gadgets and cannot, imagine performing their work without these gadgets, for instance if light goes for even 10 minutes in the offices, we struggle hard to perform the task.

We share some of our experiences; being member of some journals, where now publisher wishes to supply only soft copies of the journals, keeping an agenda of paperless working to save the number of trees and make the environment healthy. We would like to cite another example that in present trend, the publication of proceedings/compendium/ souvenir of seminar/conferences etc is being provided in the soft copies only (CD, pen drive etc). One can imagine how many of us can completely go through the soft copy which sometimes dilute the purpose of compendium/souvenir. It is important to be noticed that paperless working ameliorates the environment (by way of retaining more number of trees) but hazardous for our health (fact are well proven). Now the question is, are we for environment or environment for us or both. We recollect the line of ecology- the reciprocal relationship between the living organism and environment. More of this human life cannot be sacrificed for environment and vice-versa; therefore, it needs rational solution to maintain the equilibrium.

In an instance, when asked the Apple Chief "Steve job" by the media person, your Children must love "I Pad", he replied in a lucid manner, no they are not allowed to use the electronic gadgets at home, the amount of use of technology by the children at home is decided by us, not by them. The former Manager of Microsoft, when asked the similar line, answered the limited use of these electronic items at home. Although, we completely agreed the fact that we cannot as such do away with $e$ working environment, having enormous benefits to ease the task in our day to day life like e-ticketing, e-billing, e-governance, e-banking, e-filing, e-surveying, everification, and use of ICT etc very few to mention. Moreover, e-version requires low to no space for storage in office, home or at any place is an added advantage.

Though e-working approach is extremely important, however our perception is bit different about complete adoption of e-working in many sectors and academics is one of them (we may be wrong). We appreciate the fact of e-working in academics like use of digital library including e-books, e-journals, e-papers etc, but sometimes these things appear difficult in their practical utility. Just imagine, reading an e-book with number of pages 500 to 1000 and similar other related e-text book. The complete use of electronic format is good for some instance but, it is difficult to consider it as substitute of a complete paper books. Are we in position to continuously read an online/ e-book for a period of 2 to 3 hours that too when the facts are clearly given that continuous and more sitting with the computer/electronic gadgets can cause series of ailment or disorder.

A study at National Institute of Technology (NIT), Raurkela reveals that the dependency of people on electronic technological gadgets and services provided by these has reached such level that, without these, they cannot think a step forward in the direction of their growth. The degree of dependency is leading to addiction of the tech-devices and services. Youth is the most vulnerable group among the population to be addicted to technology. Young generation spend a large amount of their time with their tech-gadgets and services provided by them. The purposes of use in most cases are pleasure driven rather than necessity driven. Again, it reveals that addiction to tech-devices has many negative impacts on the aspects relating to mental health of the respondents and has become a causal factor in the change of life style of young participants (Mudali, 2014).

The fact of the matter is that, now a day scholars, scientists, academicians and regular readers are not visiting to the library and some time not in position to read the soft copy (e-copy) even in their computer, which is diluting the reading habits in the upcoming generation. In the present scenario, the libraries of academic institution have become redundant up-to some extent due to lack of sufficient readers. It is difficult to read a complete e-book due to obvious reasons; more of that one cannot enjoy an e-novel like a hard bound novel. We cite an example, one can easily search number of research papers in the e-domain, however to read a selected paper one wishes to get its printed version for proper and better reading so as understanding. The copious amount of information is available in e-domain, off-course we use it for immediate search but for better reading we go for the printed version of the e-text. The abundant information is available with us in e-domain, but not on the table, thus, not able to read it properly. The way people and systems operate, work, communicate, and collaborate is being transformed by e-Work. Hence, understanding 
how to design effective e-Work is fundamental to productivity and competitiveness (Nof, 2003).

The use of mobile and computer have now become essential part of our life but sometimes use of these gadgets have been observed with no proper rationale (excess use of face book, WhatsApp, etc.) which can be lethal in many ways particularly develops more obsessions to the upcoming generation. In addition, the health hazards are compound in every step of e-versions (Ahmed, 2010). We are writing this article using lap-top even realizing the impact of health hazard during constantly working in e-environment. There is a need to frame an e-gadget user policy for human safety and health hazard protection, if already not in place and needs to be disseminated to the common man of the country. E-fasting approach is another idea, where one can completely go away with use of electronic gadgets at least one day in a week. When you check the dark underbelly of technology, you will discover how your electronic gadgets can pose possible risks and hazards to your health (http://www.greenlifestylemarket.com/blog/ the-negative-effects-of-electronics-on-human-health/). With so many facets to e-working, and many of those facets subject to development potential, it is not surprising that the full expanse of the e-working term has failed to be fully acknowledged. We are not discarding the $e$ - working, but should be with utmost safety. In our opinion $e$-working is need of the time but requires equilibrium between working style and human health. Finally, we appreciate the e-working, but not at the cost of human health which is priceless.

\section{Conflict of interest statement}

Authors declare that they have no conflict of interest.

\section{References}

Ahmed, F. 2010. What are the good and bad effects of gadgets? http://www.greenlifestylemarket.com/blog/ the-negative-effects-of-electronics-on-humanhealth/.

http://www.indiastudychannel.com/resources/125598What-are-the-good-and-bad-effects-of-gadgets.aspx

Mudali, J.R., 2014. Addiction to Technological Gadgets and Its Impact on Health and Lifestyle: A Study on College Students. Thesis submitted Master's Degree in Development Studies at NIT, Raurkela.

Nof, S. Y., 2003. Design of effective e-work: Review of models, tools, and emerging challenges. Product. Plann. Control. 14(8), 681-703.

\section{How to cite this article:}

Bijalwan, A., Dobriyal, M. J. R., Chaudhry, P., 2017. e-Working environment: A present way of life. Int. J. Curr. Res. Biosci. Plant Biol. 4(1), 102-104. doi: http://dx.doi.org/10.20546/ijcrbp.2017.401.011 